\title{
EFFECTS OF EDTA, GLY-PRO-ARG-PRO, AND \\ AMINO ACID REPLACEMENT ON THE THROMBIN-CATALYZED RELEASE OF FIBRINOPEPTIDES
}

\author{
S. D. Lewis, D. L. Higgins, and J. A. Shafer \\ Department of Biological Chemistry \\ The University of Michigan Medical School \\ Ann Arbor, Michigan 48109
}

Thrombin catalyzes release of fibrinopeptide A (FPA) and fibrinopeptide B (FPB) from the $A \alpha$ - and $B \beta$-chains of fibrinogen in the conversion of fibrinogen to fibrin. It is generally believed that release of FPA occurs prior to the release of FPB. It has been proposed, however, that release of FPB can occur prior to release of FPA. ${ }^{1}$ Evidence is presented here indicating that normally very little $(<5 \%)$ of the FPB is released before FPA. Also steady state kinetic parameters for the release of FPA and FPB were evaluated using high performance liquid chromatography to determine FPA and FPB. ${ }^{2}$

Our observations of the thrombin catalyzed release of fibrinopeptides from fibrinogen from patients with fibrinogen-Petoskey support the view that FPB release occurs primarily after release of FPA. Fibrinogen-Petoskey contains equal amounts of normal $A \alpha$-chains and abnormal Aa-chains, with a His replacement for Arg-A $\alpha 16 .^{2}$ The presence of a histidyl residue instead of an arginyl residue at the scissile bond results in a dramatic decrease in the rate (150-fold at $\mathrm{pH} \mathrm{7.4)} \mathrm{of} \mathrm{thrombin} \mathrm{catalyzed} \mathrm{release} \mathrm{of} \mathrm{FPA} \mathrm{from} \mathrm{the} \mathrm{abnormal}$ $A \alpha$-chains. The FPA released from the abnormal chains has a $\mathrm{COOH}$-terminal His and can be distinguished chromatographically from normal FPA. The retarded release of FPA-Petoskey caused by the Arg $\rightarrow$ His replacement in $50 \%$ of the $A \alpha$-chains was accompanied by a delayed release of $50 \%$ of the FPB, suggesting that release of FPB prior to release of FPA must be a very slow process. If it were not, the delayed release of FPB should not have corresponded to the delayed release of FPA-Petoskey.

In addition to the release of FPA, the association of desA-fibrinogen molecules may be required to realize substantial rates of release of FPB, since EDTA and Gly-Pro-Arg-Pro, inhibitors of fibrin polymerization, inhibited the release of FPB, but did not inhibit the release of FPA.

The steady state kinetic parameters $k_{c a t}$ and $K_{m}$ were determined from fits of the kinetic data to

$$
[A \alpha] \mathrm{e} / \mathrm{V}=[\mathrm{A} \alpha] / \mathbf{k}_{\mathrm{cat}}+\mathrm{K}_{\mathrm{m}} / \mathbf{k}_{\mathrm{eat}}
$$

where $\mathrm{V}$ is the velocity of FPA release, $\mathrm{e}$ is the thrombin concentration and

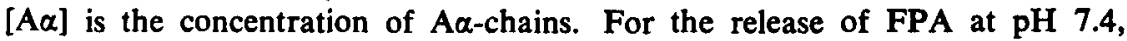
$37^{\circ} \mathrm{C}, k_{c a t}=84( \pm 4) s^{-1}, K_{m}=7.2( \pm 0.9) \mu \mathrm{M}$.

Methods were developed for direct determination of the specificity constant $\mathrm{k}_{\mathrm{cat}} / \mathrm{K}_{\mathrm{m}}$ for the thrombin catalyzed release of FPA and FPB from fibrinogen. 
When $[A \alpha] \ll K_{m A}$ and $[B \beta] \ll K_{m B}$, the Michaelis-Menten equation for the release of FPA becomes

$$
-\mathrm{d}[\mathrm{A} \alpha] / \mathrm{dt}=\mathrm{k}_{\mathrm{cat \Delta}}[\mathrm{A \alpha}] / \mathrm{K}_{\mathrm{m \Delta}}
$$

Integration yields

$$
\ln \left([A \alpha] /[A \alpha]_{0}\right)=-k_{\text {cat }} \text { et } / K_{m A}
$$

The dependence of $\ln \left([A \alpha] /[A \alpha]_{0}\right)$ on time yielded values for $k_{\mathrm{cat}} / \mathrm{K}_{\mathrm{mA}}$ that corresponded to the quotient of the separately determined values of $k_{c a t}$ and $K_{m}$. Since release of FPB occurs after FPA, the appearance of FPB follows consecutive first order kinetics according to the equation

$$
[F P B] /[F P B]_{f}=1+\left(k_{2} \exp \left(-k_{1} t\right)-k_{1} \exp \left(-k_{2} t\right)\right) /\left(k_{1}-k_{2}\right)
$$

where $k_{1}=k_{c a t} e / K_{m A}, k_{2}=k_{c a t B} e / K_{m B}$, [FPB] is the concentration of released FPB at time $t$, and $[\mathrm{FPB}]_{t}$ is the final concentration of FPB. Values of $12( \pm 2) \mu \mathrm{M}^{-1} \mathrm{~s}^{-1}$ and $4.2(0.3) \mu \mathrm{M}^{-1} \mathrm{~s}^{-1}$ for $\mathrm{k}_{\text {cat }} / \mathrm{K}_{\mathrm{mA}}$ and $\mathrm{k}_{\text {cat }} / \mathrm{K}_{\mathrm{mB}}$, respectively were obtained from fits of the kinetic data to Equations 3 and 4.

\section{REFERENCES}

1. Martinelli, R. A. \& H. A. Scheraga. 1980. Biochemistry 19: 2343-2350.

2. Higgins, D. L. \& J. A. Shafer. 1981. J. Biol. Chem. 256: 12013-12017. 